УДК 811.11-112

ББК 80

DOI: https://doi.org/10.17308/lic.2021.3/3585

\title{
ОБРАЗ ЖЕНЩИНЫ В АНГЛОЯЗЫЧНЫХ ПОСЛОВИЦАХ: СЕМАНТИЧЕСКИЙ АНАЛИЗ
}

\author{
Т. Е. Алексеева, Л. Н. Федосеева \\ Академия ФСИН России
}

\section{THE IMAGE OF A WOMAN IN ENGLISH PROVERBS: SEMANTIC ANALYSIS}

\author{
T. E. Alexeeva, L. N. Fedoseeva \\ Academy of the Federal Penitentiary Service of Russia
}

\begin{abstract}
Аннотация: в статье предлагается классификация английских пословиц с конщептом «женщина» на основе семантического анализа. Выделены группы пословиц, посвященных сочиальной роли женщины жены, матери, хозяйки; пословицы, описывающие личные качества женщины и показываюшие отношение $\kappa$ женшине в обществе. В пословицах первой группы отмечается необходимость создания семьи и важность хорошей жены для мужчины, хотя нередко жена подвергается критике, а семейная жизнь представляется как источник расходов и неприятностей. Пословиць о женщине-матери и хозяйке в основном имеют положительную коннотацию, в то время как многие личные качества женщины очениваются негативно. Судя по пословицам, которые нередко представляют точку зрения мужчин, женщине присущи тщщеславие, болтливость, расточительность, упрямство, лживость и другие отрицательные черты характера. В пословицах об интеллектуальных способностях женщины можно увидеть снисходительное отношение к ней как существу более низкой организации по сравнению с мужчиной. Отобранные пословицы могут стать аутентичным дидактическим материалом при обучении профессионально-ориентированному английскому языку в неязыковом вузе: для развития произносительных навыков и навыков выразительного чтения, при изучении грамматики. Обобщающий характер, народная мудрость, назидательный смысл пословии делают их мотивирующим стимулом для развития навыков устной и письменной речи. Благодаря своей логической завершенности и образности пословицы могут использоваться в курсе стилистики английского языка в языковом вузе, например, в качестве иллюстрации различных стилистических приемов: метафоры, сравнения, эпитета, параллельных конструкиий, антитезы и $р$.
\end{abstract}

Ключевые слова: английские пословицы, женщина, личные качества, семантический анализ, практическое применение.

Abstract: the article deals with the English proverbs related to a woman. The aim of investigation is to analyze these proverbs from the viewpoint of their meaning. As a result of semantic analysis the authors have classified the proverbs into two groups: those devoted to the social roles of a woman - a wife, a mother, a housewife, and those describing personal traits of a female. The proverbs emphasize the necessity to create a family and the importance of a good wife for a man, though marriage is often blamed as a cause of big trouble. Most proverbs about a woman as a mother and a housewife have positive connotations while the personal characteristics of a female are mostly negative. Being for the most part the expression of men's views, proverbs portray women as conceited, talkative, extravagant, obstinate and deceitful creatures. Intellectual abilities of a woman are presented in a way that reveals the condescending attitude to her wisdom, instinct, advice. The proverbs analyzed may be used for teaching English for special purposes, to develop pronunciation and grammar skills. Inherent generalization, popular wisdom and didactic nature of proverbs make them a strong incentive for developing students'oral and writing skills. Thanks to their imagery, proverbs may be used to illustrate the stylistic devices of metaphor, simile, epithet, parallelism, etc. in the course of stylistics of the English language.

Key words: English proverbs, woman, personal traits, semantic analysis, practical use.

(C) Алексеева Т. Е., Федосеева Л. Н., 2021

Контент доступен под лицензией Creative Commons Attribution 4.0 License.

The content is available under Creative Commons Attribution 4.0 License. 


\section{Введение}

Многие лингвисты занимались изучением пословиц, в том числе пытаясь дать наиболее точное определение этому виду народного творчества. Проведя анализ ряда определений паремий [1-6], мы сформировали собственный перечень характеристик, которые превращают изречение в пословицу: грамматическая и логическая завершенность; особое ритмо-интонационное и фонетическое оформление; афористическая краткость и меткая образность; обобщающий характер и назидательный поучительный смысл; фиксация практического опыта народа и его оценки определенных жизненных явлений; устойчивость в речевом обиходе. Эти особенности пословиц делают их объектом изучения специалистами в области лингвистики, истории, культурологии, методики преподавания языков.

\section{Материалы и методы}

Изучение пословичного фонда английского языка [7-11] показало, что пословицы охватывают практически все стороны жизни человека: бытовые проблемы и семейные отношения; личные качества и общественные взгляды на те или иные явления. Взаимоотношения между мужчиной и женщиной не являются исключением.

В рамках нашего исследования мы отобрали и проанализировали около 300 англоязычных пословиц, в центре которых находится женщина. Статистический анализ показал, что чаще всего в анализируемых паремиях встречаются лексемы “woman/women" (157 ра3) и "wife/wives" (66 раз).

Проведенный нами анализ содержания пословиц, содержащих концепт «женщина», позволил классифицировать их следующим образом: место женщины в обществе (женщина-жена, женщина-мать, женщина-хозяйка) и личностные качества женщины; при этом многие пословицы наглядно показывают отношение общества к женщине.

\section{Результаты}

На протяжении столетий женщина считалась существом, по всем параметрам уступающим мужчине. В обществе, где доминировали мужчины, женщине отводилась роль покорной жены, заботливой матери, хорошей хозяйки - хранительницы семейного очага, что нашло свое отражение в пословицах. Так, в целом ряде паремий с ключевым словом wife отмечается важность хорошей жены в семейной жизни: Wife is a key of the house / Жена-это ключ от дома; A good wife's a goodly prize / Хорошая жена - это большая удача; A good wife makes a good husband / $\mathrm{y}$ хорошей жены и муж хорош; A good wife and health is a man's best wealth / Хорошая жена и здоровье лучшее богатство мужчины; A man's greatest treasure is his wife - she is a gift from the Lord / Самое большое богатство мужчины - его жена; она дар божий.

В некоторых пословицах акцентируется необходимость для мужчины создать семью, при этом женитьба не есть благо: Wives must be had, be they good or bad / Жена должна быть: неважно, хорошая или плохая; A man without a woman / wife is but half a man / Мужчина без женщины / жены - только наполовину мужчина; Needles and pins, needles and pins: when a man marries his trouble begins / Иглы и булавки, иглы и булавки: когда мужчина женится, у него начинаются неприятности.

О том, что женщина может главенствовать в семье и даже подчинить себе мужа, говорится в следующих пословицах: He that has a wife has a master / У кого есть жена, у того есть хозяин; Man is the head, but woman turns it / Мужчина голова, но женщина вертит ею; An obedient wife commands her husband / Послушная жена командует мужем; $A$ woman can't drive her husband but she can lead him / Женщина не может командовать своим мужем, но может управлять им.

Женщина-мать - положительный образ в пословичном фонде любого народа, и английский язык не исключение: A mother's love never ages / Любовь матери никогда не стареет; A mother's love is best of all / Любовь матери самая крепкая; A man's mother is his own God / Для мужчины мать - это божество; The mother's breath is always sweet / Дыхание матери всегда согревает; There's only one pretty child in the world and every mother has it / Для матери ее ребенок самый лучший.

Однако мать может сыграть отрицательную роль в жизни своих детей: The mother of coward doesn't worry about him / Мать труса может о нем не беспокоиться; Mother's darlings make but milksop heroes / Из маменькиных сынков герои не вырастают.

В женщине-хозяйке ценятся умение поддерживать уют и чистоту в доме, забота о членах семьи: $A$ house well-furnished makes a good house-wife / Хорошо обставленный дом говорит о хорошей хозяйке; Үои know a good housekeeper by her windows / Хорошую хозяйку можно узнать по окнам; The foot on the cradle and hand on the distaff is the sign of a good housewife / Нога на люльке и пряжа в руках - так должна выглядеть хорошая хозяйка.

«Без хозяина дом - сирота», - гласит русская пословица, и ей вторит английская: «If the husband be not at home, there is nobody». Однако важная роль хозяйки в доме отмечается в ряде других пословиц: Where there is no wife, there is no home / Где нет жены, там нет и дома; Woeful is the household that wants a woman / Печален тот дом, где нет женщины; House 
goes mad when woman gads / В доме все вверх дном, когда там нет женщины.

В следующую семантическую группу входят пословицы, раскрывающие отрицательные черты характера женщины, чаще всего отражающие стереотипное представление о ней как о тщеславной, болтливой, сварливой, корыстной, недалекой особе.

О том, как важно для женщины быть красивой, говорится в пословицах: Every woman would rather be beautiful than good / Любая женщина предпочтет быть красивой, чем доброй; Tell a woman she is fair, and she will soon turn fool / Сделай женщине комплимент - и она поглупеет; Women are vain: they 'd rather be pretty than have a good brain / Женщины тщеславны; они предпочитают быть красивыми, нежели умными.

Судя по некоторым паремиям, женщина уделяет слишком большое внимание своей внешности, нередко в ущерб семье: The wife that loves the looking-glass hates the saucepan / Женщина, которая любит зеркало, ненавидит кастрюлю; The more women look in their glass, the less they look to their house / Чем больше женщина смотрится в зеркало, тем меньше заботится о доме; A woman, the more curious she is about her face, the more careless about her house / Чем больше женщина заботится о своем лице, тем меньше занимается своим домом.

Красота недолговечна, что огорчает женщину, которая старается продлить молодость и даже скрывает свой возраст: Prettiness dies first / Красота умирает первой; Grace will last, beauty will blast / Добродетель останется - красота исчезнет; The hell of women is old age / Старость - это преисподняя для женщины; The only secret a woman can keep is her age / Единственный секрет, который способна хранить женщина, - это ее возраст; The longest five years in a woman's life is between twenty-nine and thirty / Самые длинные пять лет в жизни женщины между 29 и 30 годами.

С точки зрения общества, красота не является достоинством, так как красивая жена - источник неприятностей: A fair wife and frontier castle breed quarrel / Красивая жена и приграничный замок порождают раздоры; The nice wife and back door rob the house / Красивая жена и задняя дверь грабят дом; If you marry a beautiful woman, you marry trouble / Если ты женишься на красивой женщине, жди неприятностей; He that has a white horse and a fair wife, never wants trouble / Красивая жена и белая лошадь - причины многих проблем.

Утверждается, что для счастливой семейной жизни предпочтительна некрасивая жена: Plain women are as safe as churches / Некрасивые женщины так же безопасны, как церкви; The uglier the woman, the better the house-wife / Чем некрасивее жена, тем лучше из нее хозяйка; An ugly wife and a lean piece of ground protect the house / Некрасивая жена и скудный клочок земли защищают дом.

Одна из черт характера, которая раздражает в женщине, - ее болтливость. Поэтому велико число пословиц, посвященных неумению женщины хранить тайну, ее склонности к сплетням: The woman's tongue is the last thing about her that dies / У женщины язык умирает последним; A woman's sword is her tongue, and she does not let it rust / Оружие женщины - ее язык, и она не даст ему заржаветь.

Упрямство и мстительность - вот отрицательные личные качества стереотипизированной женщины: Forbid a thing, and that women will do / Запрети что-нибудь - и женщина это сделает; $A$ woman's vengeance knows no bounds / Месть женщины не знает границ; Hell hath no fury / wrath like a woman scorned / Фурия в аду - ничто в сравнении с брошенной женщиной.

Судя по некоторым пословицам, для женщины характерны злобность и ворчливость, вздорный и непредсказуемый нрав: Two women in the same house can never agree / Две женщины в одном доме никогда не найдут согласия; No war without a woman / He бывает войны без женщины; There was never a conflict without a woman / Все ссоры из-за женщин; There's hardly a strife in which a woman has not been a prime mover / Едва ли найдется ссора, в которой женщина не была бы первопричиной.

Следующие пословицы утверждают, что женщине нельзя доверять, поскольку ей свойственны притворство и лживость: Trust not a woman when she weeps / Не доверяй женщине, когда она плачет; Women naturally deceive, weep and spin / Женщины легко обманывают, плачут и прядут; Women laugh when they can, and weep when they will / Женщины смеются, когда могут, и плачут, когда захотят; The laughter, the tears and the song of a woman are equally deceptive / Смех, слезы и пение женщины одинаково обманчивы; A man should never trust a woman, even if she has borne him seven children / Мужчине никогда не следует доверять женщине, даже если она родила ему семерых детей.

Среди недостатков женщины упоминается ее расточительность: Mills and wives are ever wanting / Мельницам и женам всегда чего-то не хватает; Wine and wenches empty men's purses / Вино и женщины опустошают кошельки мужчин; It is cheaper to find a wife than to feed a wife / Дешевле найти жену, чем прокормить ее.

Ocобое место в описании женщины занимают пословицы о ее интеллекте/мудрости, в чем ей зачастую вовсе отказано: Women have long hair and short brains / У женщины волос долог, а ум короток; $A$ woman's thoughts are afterthoughts и Women's wisdom arrives after the event / Женщина задним умом крепка; When an ass climbs a ladder, we may find wisdom in a 
woman / Когда осел взберется по лестнице, женщина, может, и поумнеет.

Невысоко ценятся советы женщины, хотя иногда мужчине лучше к ним прислушаться: Women's counsel is cold и A woman's advice is best at a dead lift / Совет женщины бесполезен. Иногда снисходительно признается, что совет женщины может быть полезен (A woman's counsel is sometimes good), и хотя совет женщины не бог весть что, но дурак тот, кто им не воспользуется (A woman's advice is no great thing, but he who won't take it is a fool).

Признается, что женская интуиция нередко оказывается сильнее мужской: Women's instinct is often truer than men's reasoning / Интуиция женщины часто правильнее мужских доводов; A woman's guess is much more accurate than man's certainty / Женская догадка намного точнее, чем мужская уверенность.

Считается, что образование для женщины не нужно и даже вредно: Good wives and good soldiers should be ignorant / Хорошая жена и хороший солдат должны быть безграмотными; A morning sun, and a wine-bred child, and a Latin-bred woman, seldom end well / Утреннее солнце, дитя пьяного зачатия и образованная женщина редко хорошо кончают.

Таким образом, женщине, которая всегда считалась существом низшей организации, свойственны практически все имеющиеся пороки. Приведенные выше пословицы уже сформировали довольно неприглядный образ женщины, при этом существует большая группа паремий, где женщину открыто называют злом (evil) и приравнивают к нечистой силе (devil, Satan, dragon): A woman is man's evil / Женщина - это зло для мужчины; Women are necessary evil / Женщины - это неизбежное зло; Women are the root of all evil / Женщины - корень всего зла; Women are the devil's net / Женщины - это инструмент дьявола; Devil is dead when there is a wife / Дьявол мертв, когда есть жена; There is no devil so bad as a she-devil / Нет дьявола хуже, чем дьяволица; Women are the snares of Satan / Женщины - это ловушки сатаны.

В редких пословицах, которые хронологически относятся к более позднему периоду, когда отношение к женщине стало меняться, отмечается ее положительная роль: Behind every successful man is a woman / За каждым успешным мужчиной стоит женщина; Behind every great man there is a great woman / 3a каждым великим мужчиной стоит великая женщина.

\section{Заключение}

Подводя итог нашему исследованию, можно сделать вывод, что подавляющее большинство пословиц, посвященных женщине, создавалось в то время, когда в обществе было распространено отношение к женщине как существу низшему по сравнению с мужчиной. Пословицы отражают положение женщины, полностью зависимой от мужа или отца, ее роль в обществе состоит исключительно в выполнении обязанностей жены, матери, хозяйки. Признается, что хорошая жена составляет лучшее сокровище для мужа, что мать играет ключевую роль в жизни ребенка, что без хозяйки дом сирота. Однако в описании личностных качеств женщины превалируют критические, негативные оценки: утрируются, преувеличиваются такие черты, как болтливость, ворчливость, притворство; невысоко ценятся ум и образованность женщины; снисходительность сквозит в описании ее красоты и привлекательности. Следует отметить, что в последнее время положение женщины в обществе коренным образом меняется и появляются новые, хотя и немногочисленные, пословицы, представляющие женщину в более привлекательном свете. Однако им еще предстоит пройти проверку временем, с тем чтобы обрести устойчивость в речевом обиходе и стать пословицами в настоящем смысле этого слова.

\section{Практическая значимость}

Полученный материал может быть использован при обучении английскому языку как на специализированных факультетах, так и в профессиональноориентированных курсах иностранного языка в неязыковых вузах. В частности, благодаря своей краткости, ритмической и фонетической организации ряд пословиц может стать фонетической зарядкой или упражнением для развития навыков чтения вслух: $A$ good wife and health is a man's best wealth; A cheerful wife is the joy of life; Women are vain: they 'd rather be pretty than have a good brain.

Поскольку пословицы отличаются разнообразием встречающихся в них грамматических форм, они могут послужить аутентичным примером их употребления (в отличие от искусственно созданных моделей в традиционных учебниках):

- притяжательный падеж существительных: $A$ mother's love never ages / Материнская любовь не стареет; A man's mother is his own God / Для мужчины мать - это его бог; A blind man's wife needs no paint I Жене слепого не надо краситься;

- модальные глаголы: Women laugh when they can, and weep when they will; Good wives and good soldiers should be ignorant / Хорошие жены и хорошие солдаты не должны быть образованными; Men must work and women must weep / Мужчины должны работать, а женщины - плакать;

- степени сравнения и сравнительные обороты: It is cheaper to find a wife than to feed a wife; A woman's guess is much more accurate than man's certainty / Женская догадка намного точнее мужской уверенности; Plain women are as safe as churches / Некрасивые 
женщины в безопасности, как церкви; Most men get as good a wife as they deserve / Большинство мужчин получают такую жену, какую заслуживают.

Грамматическая завершенность пословиц позволяет им стать иллюстрацией различных структур предложений:

- с вводным оборотом there is: Where there is no wife, there is no home / Там, где нет женщины, нет дома; Whenever there is a woman, there is gossip / Там, где есть женщина, есть сплетни; There was never a conflict without a woman / Все ссоры из-за женщин;

- с местоимением it в качестве подлежащего в безличных предложениях: It's a woman's privilege to change her mind / Привилегия женщины-менять свое мнение; It requires much to keep a mill useful, and a wife fine / Многое потребуется, чтобы мельница работала, а женщина была счастлива;

- со сравнительной конструкцией типа the more ... the better...: The uglier the woman, the better the house-wife / Чем некрасивее жена, тем лучше из нее хозяйка; The more women look in their glass, the less they look to their house / Чем больше женщина смотрится в зеркало, тем меньше она следит за порядком в доме; A woman, the more curious she is about her face, the more careless about her house / Чем больше женщина думает о своей внешности, тем меньше она заботится о доме.

Большинство пословиц отличается лаконичностью, т. е. они представляют собой простые предложения, построенные в соответствии с порядком слов английского предложения, однако существуют более сложные изречения, которые могут быть использованы для структурно-семантического анализа: The happiest wife is not she that gets the best husband but she that makes the best of that which she gets / Самая счастливая жена не та, у которой самый лучший муж, а та, которая наилучшим образом использует то, что имеет.

Так как пословицы отражают опыт и мудрость создавшего их народа, многие из них могут послужить источником устного обсуждения на занятии или стать темой небольшого эссе, например, задание может быть сформулировано следующим образом:

- прокомментировать идею пословицы (The mother of coward doesn't worry about him / Мать труса может о нем не волноваться);

- объяснить смысл (A deaf husband and a blind wife are always a happy couple / Глухой муж и слепая жена всегда счастливы в браке);

- согласиться или не согласиться с содержанием (Every woman would rather be beautiful than good / Любая женщина предпочтет быть красивой, а не хорошей).

Являясь жанром народного творчества, пословицы отличаются образностью, нередко содержат вы- разительные средства, изучаемые в курсе дисциплины «Стилистика английского языка», и, следовательно, могут быть предложены в качестве иллюстрации того или иного стилистического приема:

- метафоры: A woman's sword is her tongue, and she does not let it rust / Мечом женщины является ее язык, и она не даст ему ржаветь;

- сравнения: A man without a woman is like a ship without a sail / Мужчина без женщины как корабль без паруса;

- эпитета: An obedient wife commands her husband / Послушная жена командует своим мужем;

- параллельных конструкций: Men make houses, women make homes / Мужчины строят дома, а женщины создают в них уют;

- антитезы (противопоставления): The wife that loves the looking-glass hates the saucepan / Жена, которая любит зеркало, ненавидит кастрюли;

- анафоры (повтора одинаковых звуков, слов, синтаксических конструкций): Like mother, like daughter / Какова мать, такова и дочь и т. д.

Итак, полученный материал можно использовать для решения различных дидактических задач: в практическом курсе английского языка в языковом и неязыковом вузе при формировании грамматической компетенции, для развития навыков устной и письменной речи. Предложенная нами классификация пословиц по семантическому принципу может быть использована в курсе английского языка на языковых факультетах, например при изучении темы «Семейные отношения», «Личные качества человека» и др.

\section{ЛИТЕРАТУРА}

1. Словарь-справочник по педагогическому речеведению. Изд. 2-е, испр. и доп. / под ред. Т. А. Ладыженской и А. К. Михальской. М. : Флинта, Наука, 1998. 312 с.

2. Ахманова О. С. Словарь лингвистических терминов. М. : Либроком, 2018. 576 с.

3. Жеребило Т. В. Термины и понятия лингвистики : Лексика. Лексикология. Фразеология. Лексикография : словарь-справочник. Назрань : Пилигрим, 2011. 197 с.

4. Нелюбин Л. Л. Толковый переводоведческий словарь. 3-е изд., перераб. М. : Флинта: Наука, 2003. $320 \mathrm{c}$.

5. Ефремова T. Ф. Новый словарь русского языка. Толково-словообразовательный : в 2 т. М. : Рус. яз., 2000. $1209 \mathrm{c}$.

6. Энциклопедический словарь : в 86 т. / изд. Ф. А. Брокгауз, И. А. Ефрон. СПб. : ПОЛРАДИС, 1993.

7. Kerschen L. American Proverbs about Women : a Reference Guide. Westport, Conn : Greenwood Press, 1998. 200 p.

8. Simpson J. A. Concise Oxford Dictionary of Proverbs. Oxford : Oxford University Press, 2003. 364 p.

9. Oxford Dictionary of Proverbs. URL: oxfordreference.com> 
10. Manser M. Dictionary Of Proverbs. URL: archive. org>details/ DictionaryOfProverbs 201303

11. Сташкова М. А. Функционирование пословиц и антипословиц с гендерным компонентом в современном английском языке : дис. ... канд. филол. наук. М., $2015.231 \mathrm{c}$

\section{REFERENCES}

1. Slovar '-spravochnik po pedagogicheskomu rechevedeniyu [Dictionary-reference book in pedagogical speech studies]. Izd. 2-e, ispr. i dop. Ed. by T. A. Lady zhenskoj and A. K. Mixal'skoj. M.: Flinta, Nauka, 1998. 312 p.

2. Axmanova O. S. Slovar lingvisticheskix terminov [Dictionary of linguistic terms]. M.: Librokom, 2018. 576 p.

3. Zherebilo T. V. Terminy $i$ ponyatiya lingvistiki: Leksika. Leksikologiya. Frazeologiya. Leksikografiya: Slovar'-spravochnik [Terms and concepts of linguistics: Vocabulary. Lexicology. Phraseology. Lexicography: Dictionary-reference book]. Nazran`: OOO «Piligrim», 2011. 197 p.

4. Nelyubin L. L. Tolkovy ’j perevodovedcheskij slovar [Explanatory dictionary of translation studies]. 3-e izd., pererab. M.: Flinta: Nauka, 2003. 320 p.

Академия ФСИН России

Алексеева T. Е., кандидат педагогических наук, доиент кафедры иностранных языков

E-mail: tat-alexeeva@yandex.ru

Федосеева Л. Н., доктор филологических наук, доиент, заведующая кафедрой иностранных языков

E-mail:LN-FEDOSEEWA@yandex.ru

Поступила в редакциюю 18 апреля 2021 г.

Принята к публикаџии 15 июня 2021 г.

\section{Для цитирования:}

Алексеева Т. Е., Федосеева Л. Н. Образ женщины в англоязычных пословицах: семантический анализ // Вестник Воронежского государственного университета. Серия: Лингвистика и межкультурная коммуникация. 2021. № 3. C. 89-94. DOI: https://doi.org/10.17308/ lic. $2021.3 / 3585$
5. Efremova T. F. Novy j slovar` russkogo yazy `ka. Tolkovo-slovoobrazovatel 'ny $j$ [New dictionary of the Russian language. Explanatory and word building]: in 2 v. M.: Rus. yaz., 2000. 1209 p.

6. E'nciklopedicheskij slovar' [Encyclopedic dictionary]: In 86 v. Izd. F. A. Brokgauz, I. A. Efron. SPb.: POLRADIS, 1993.

7. Kerschen L. American Proverbs about Women: a Reference Guide. Westport, Conn: Greenwood Press, 1998. $200 \mathrm{p}$.

8. Simpson J. A. Concise Oxford Dictionary of Proverbs. Oxford: Oxford University Press, 2003. 364 p.

9. Oxford Dictionary of Proverbs. Available at: oxfordreference.com>

10. Manser M. Dictionary Of Proverbs. Available at: archive.org>details/DictionaryOfProverbs201303

11. Stashkova M. A. Funkcionirovanie poslovicz $i$ antiposlovicz s genderny 'm komponentom $v$ sovremennom anglijskom yazy ke [Functioning of proverbs and antiproverbs with gender component in modern English language]. dis. ... kandidata filologicheskix nauk. M., 2015. $231 \mathrm{p}$.

Academy of the Federal Penitentiary Service of Russia Alexeeva T. E., Candidate of Pedagogical Sciences, Associate Professor of the Foreign Languages Department E-mail: tat-alexeeva@yandex.ru

Fedoseeva L. N., Doctor of Philology, Associate Professor, Head of the Foreign Languages Department

E-mail:LN-FEDOSEEWA@yandex.ru

Received: 18 April 2021

Accepted: 15 June 2021

\section{For citation:}

Alexeeva T. E., Fedoseeva L. N. The image of a woman in English proverbs: semantic analysis. Proceedings of Voronezh State University. Series: Linguistics and Intercultural Communication. 2021. No. 3. Pp. 89-94. DOI: https:// doi.org/10.17308/lic.2021.3/3585 